\title{
Relato de Experiência de Blended Learning: O Moodle e o Facebook Como Ambientes de Extensão da Sala de Aula Presencial
}

\author{
Renata Araújo ${ }^{1}$, Thelma Panerai ${ }^{2}$ \\ ${ }^{1}$ Mestranda no Programa de Educação Matemática e Tecnológica - Universidade Federal de \\ Pernambuco (UFPE) \\ ${ }^{2}$ Departamento de Métodos e Técnicas de Ensino e Docente do Programa de Educação \\ Matemática Matemática e Tecnológica- Universidade Federal de Pernambuco (UFPE) \\ (renatakellyead@gmail.com, tpanerai@gmail.com)
}

\begin{abstract}
This work presents itself as an experience report Blended Learning with students of 8 th period of attendance Course Pedagogy in the elective course Introduction to Distance Education of a University, where Moodle and Facebook have been consolidated as environments extension of classroom attendance. We discuss the possibilities and challenges of using these learning environments as a way to continue the educational process beyond the classroom, from the conception of the students, who considered such an experience as constructive, innovative and supportive of new educational possibilities in their practice teaching as future teachers.
\end{abstract}

Key Words: Blended Learning; Moodle; Facebook; Pedagogical Environments.

Resumo. O presente trabalho se apresenta como um relato de experiência de Blended Learning com os discentes do $8^{\circ}$ período do Curso presencial de Licenciatura em Pedagogia, na disciplina eletiva de Introdução à Educação a Distância de uma Universidade Federal, onde o Moodle e o Facebook foram consolidados como ambientes de extensão da sala de aula presencial. Discutiremos as possibilidades e os desafios do uso destes ambientes pedagógicos como forma de continuidade do processo educativo, para além da sala de aula, a partir da concepção dos discentes, que consideraram tal experiência como construtiva, inovadora e favorecedora de novas possibilidades educativas em suas práticas pedagógicas como futuros docentes.

Palavras Chave: Blended Learning; Moodle; Facebook; Ambientes Pedagógicos. 


\section{Introdução}

O processo evolutivo da humanidade foi demarcado pelas mudanças tecnológicas existentes, sendo as tecnologias tão antigas quanto à espécie humana. (Kenski, 2007, p.15). De tal modo, a emergência das tecnologias digitais de informação e comunicação nos encaminharam a sociedade digital, do conhecimento, das redes, consolidando um transformações significativas na forma de ser e está na sociedade através da Cibercultura, denominada com (Lemos, 2003) "a forma sociocultural que emerge da relação simbiótica entre a sociedade, a cultura e as novas tecnologias".

É com o surgimento do Ciberespaço, novo espaço comunicativo possibilitado a partir da internet, é possível atualmente vislumbrarmos um novo olhar para a educação, a partir da possibilidade de construção de conhecimento com a Educação a distância. De acordo com (Pereira e Teixeira, 2011) "um dos grandes desafios da educação na atualidade é gerenciar esse grande fluxo de informações e torná-las significativas" e por tal repensar o processo educativo se faz preponderante neste cenário atual.

Atualmente já se discute uma imbricação das modalidades educativas presencial e virtual, como modo de maximizar a construção do processo de ensino aprendizagem. Assim, emerge o Blended Learning (B-learning) também denominada como aprendizagem hibrida, é vista como uma modalidade em que há uma convergência das vivências da sala de aula "presencial" para o "virtual", possibilitando docentes e discentes construírem o conhecimento de forma mais plural e participativa. Emergindo num contexto de fluxos informacionais mais descentralizados, a B-Learning no contexto brasileiro foi impulsionada a partir da portaria $\mathrm{n}^{\circ}$ 2.253/2001, a qual permite às instituições a direcionar 20\% de sua carga horária a inclusão de atividades não presenciais.

Sendo considerada como uma das dez maiores tendências da indústria do conhecimento (Graham, 2005 apud Tori, 2009, p.121) a Blended Learning pode potencializar o processo de aprendizagem, unindo formas diversas de se fazer educação possibilitando aos alunos autoria, colaboração e flexibilidade nos estudos. De tal modo, este trabalho busca 
apresentar o relato de uma experiência com Blended Learning, onde se buscou não apenas ter como extensão da sala de aula o Ambiente Virtual de Aprendizagem Moodle, como também as redes sociais na internet, como mais um espaço de trocas significativas e construção interativa e colaborativa do saber, espaço este que muito atrai os nativos digitais.

\section{O Moodle:Novas Perpectivas no Processo Educativo}

O Moodle (Modular Object-Oriented Dynamic Learning Environment) é uma plataforma criada para favorecer os processos de ensino e aprendizagem a distância. Esta é uma plataforma de código aberto (disponibilizado gratuitamente, podendo ser adaptado e personalizado segundo os interesses da instituição que o adota) e que tem sido muito utilizada nas universidades para cursos online e para apoio a cursos presenciais. De acordo com Sabbatini (2012), o Moodle é extremamente robusto, suportando dezenas de milhares de alunos em uma única instalação. Este autor revela que a Open University (Inglaterra) adotou o Moodle para seus mais de 200.000 estudantes espalhados pelo mundo. Da mesma forma, a nossa Universidade Aberta do Brasil ${ }^{1}$ (UAB) também adotou este sistema para seus cursos a distância. Os Ambientes Virtuais de Aprendizagem trazem novas perspectivas para o processo de ensino aprendizagem, o que requer dos docentes um olhar inovador, não apenas na forma como se entende a educação, mas principalmente na forma como ocorre a prática, garantindo uma verdadeira mudança de paradigma nesta modalidade educativa, indo além do tradicionalismo a que se encontra interligada.

\section{O Facebook como Espaço de Construção do Conhecimento}

De acordo com Wasserman e Faust, 1994; e Degenne e Forse, 1999 apud RECUERO, 2009 , p. 24) rede social "é um conjunto de dois elementos: atores e conexões", o que compreendemos à luz do autor ser um conjunto de pessoas, grupos que interagem, formam

\footnotetext{
${ }^{1}$ A Universidade Aberta do Brasil "é um sistema integrado por univ ersidades públicas que oferece cursos de nível superior para camadas da população que tem dificuldades de acesso à formação universitária, por meio do uso da metodologia da educação a distância”. (BRASIL, 2010).
} 
laços sociais. Segundo (MANSUE, Andre; CARVALHO, Rogerio; BIAZUS, Maria, 2011) "estas redes caracterizam-se por uma infraestrutura em teia, através de sistemas que se interconectam, integram e se inter relacionam, passando a ter uma importância cada vez maior para a sociedade contemporânea”.

Segundo Recuero (2009), normalmente os estudos que se referem às redes sociais estão dirigidos à interação entre os atores envolvidos no processo, os laços estabelecidos entre eles e o capital social criado pelas interações. Neste sentido, Kerbauy e Santos (2011 apud Haguenauer, 2011) afirmam que as concepções sobre redes sociais parecem ter um ponto em comum: falar de redes pressupõe um trabalho articulado com a noção de troca de informações.

Rabello e Haguenauer (2011) assinalam que o aprendizado eletrônico (e-learning) e, mais recentemente, a aprendizagem móvel (m-learning), estão mudando radicalmente os ambientes e contextos de aprendizagem. Ferramentas como os ambientes virtuais de aprendizagem (AVAs) e as redes sociais (Orkut, Facebook, Twitter, dentre outras) favorecem que a construção de conhecimento e a aprendizagem se expandam para além das fronteiras geográficas e do sincronismo que caracterizam a aprendizagem em ambiente presencial. Rabello e Haguenauer (2011) mostram que, atualmente, várias universidades possuem páginas na rede social a fim de promover uma boa comunicação com alunos e futuros alunos. Apesar de todas as possibilidades trazidas pelo Facebook, que podem tornar o espaço de aprendizagem não mais centrado em um lócus específico, a sala de aula, são poucas as experiências na literatura que demonstram o uso das redes sociais como ambiente pedagógico, principalmente no nível superior de ensino, segundo recente pesquisa Rabello e Haguenauer (2011), na Revista EducaOnline. Por tal a importância desta pesquisa como forma de divulgação de práticas inovadoras no processo de ensino aprendizagem, o que pode motivas novas práticas e pesquisas neste universo do Blended Learning, que de certa forma é inovador na literatura. 


\section{Metodologia}

Este estudo se revela como um estudo de caso, uma vez que, de acordo com olhar de Laville e Dione (1999, p. 155) 'É um estudo de um caso, talvez o de uma pessoa, mas também o de um grupo, de uma comunidade, de um meio, ou então fará referência a um acontecimento especial". A abordagem desta pesquisa é qualitativa, pois esta se mostra como sendo a mais coerente para os estudos em âmbito educativo, pertencente às ciências humanas, Segundo Minayo (2001, p. 21), ela trabalha com o universo dos significados, dos motivos, das aspirações, das crenças, dos valores e das atitudes, e, assim sendo, pode retratar de modo mais apropriado o nosso objeto de estudo.

Realizamos um questionário, com perguntas de múltipla escolha e abertas aos discentes de modo a compreender suas concepções sobre acerca desta experiência de Blended Learning. Segundo Laville e Dione (1999, p. 183), essa é uma técnica para saber a opinião das pessoas baseada em uma série de perguntas sobre o tema visado, escolhidas em função da hipótese do objeto de estudo. Realizamos o questionário através da ferramenta Google Docs ${ }^{2}$. Consideramos importante usar tecnologias digitais para a coleta de dados. Com a finalidade de termos uma visão mais aprofundada das concepções dos discentes, e contrastar suas colocações com a prática vivenciada na disciplina, buscamos realizar também uma observação sistemática, onde acompanhamos os momentos de aulas presenciais da disciplina Introdução à Educação a Distância, com carga horária de 60 horas. Essas aulas deveriam acontecer no período de março a junho 2012, porém, devido à greve das universidades federais, realizamos coleta de março a maio. Além disto, realizamos uma etnografia virtual, que é uma metodologia de pesquisa utilizada para pesquisas na internet. Segundo Hine (2000), essa metodologia tem como princípio "a presença prolongada do etnógrafo em seu campo de estudo, combinado com um profundo compromisso com a vida diária das pessoas nesse campo". A etnografia se caracteriza como uma imersão do pesquisador, uma observação no espaço virtual, de modo a compreender as nuances deste contexto cibercultural consoante ao objeto estudado. Assim, buscamos compreender as

\footnotetext{
${ }^{2}$ É um pacote de aplicativos do Google que permite aos usuários criar e editar documentos
} online, ao mesmo tempo, colaborando em tempo real com outros usuários. Fonte: Wikipedia 
formas de participação dos discentes no Ambiente Virtual de Aprendizagem Moodle e na Rede Social Facebook, ambos utilizados como ambientes pedagógicos na disciplina referida, para entender de maneira aprofundada esta experiência de Blended Learning.

Os sujeitos da pesquisa são os 24 discentes do $8^{\circ}$ período, semestre 2012.1, do curso presencial de Licenciatura em Pedagogia de uma universidade federal, todos participantes da disciplina eletiva Introdução à Educação a Distância.

\section{Relato de Experiência}

A disciplina Introdução à Educação a Distância é uma disciplina eletiva, com carga horária de 60 horas, disponível no semestre 2012.1, no $8^{\text {ao }}$ período do Curso Presencial de Licenciatura em Pedagogia de uma Universidade Federal. Tal disciplina visa explicar os fenômenos relativos à Educação a Distância, desde o seu emergir e concepção até a forma como é posta nos dias atuais. Por seu caráter temático inovador, a mesma, que deveria se dar de forma presencial, foi proposta a partir do Blended Learning, o qual, segundo (TORI, 2009), é um modelo de ensino e aprendizagem híbrido, permeado por momentos presenciais e virtuais, onde docentes e discentes estendem o debate de sala de aula para o âmbito virtual, construindo o conhecimento de forma colaborativa, contínua e atemporal.

Percebendo a importância e a motivação das redes sociais para a maioria dos jovens e de como são escassas as experiências pedagógicas com estas redes, resolvemos colocar em prática o desafio de propor o Facebook como um diferencial a mais da sala de aula, juntamente com o Moodle - utilizado nos semestres anteriores, nesta disciplina. Neste sentido, a disciplina teve como proposta metodológica o desenvolvimento de um diálogo permanente com os discentes, indo e vindo do presencial ao virtual, com atividades realizadas tanto em sala de aula como aulas substituídas por debates via fórum de discussão, chats e atividades de pesquisa e compartilhamento nos ambientes pedagógicos utilizados: o Moodle e o Facebook.

O trabalho nesta disciplina foi direcionado para que as discussões semanais não se restringissem ao espaço de sala de aula, mas que fossem continuadas dentro dos ambientes pedagógicos propostos. Deste modo, depois dos debates em sala de aula, referentes aos conteúdos específicos da disciplina, eram realizados fóruns temáticos para que as discentes 
pudessem dar continuidade à discussão no decorrer da semana, aprofundando os temas trabalhados através de pesquisas e debates colaborativos.

Assim, a partir da proposta de realizar a disciplina utilizando uma metodologia construtivista, em que os alunos pudessem construir o conhecimento de maneira colaborativa, interativa, compartilhada, exercendo sua autonomia e capacidade crítica, de maneira inovadora, com a inclusão do Facebook e do Moodle, propondo uma avaliação formativa e que considerasse as interações realizadas pelos discentes nestes ambientes, de modo a incentivar a participação neste novo universo educativo que é o educar a distância, apresentaremos a seguir a análise dos dados obtidos nesta experiência.

Inicialmente, apresentamos no primeiro momento da disciplina as discentes a proposta da disciplina e discutimos como se daria o caminhar da mesma. Após este, marcamos dois momentos no laboratório de informática, no intuito de incluir as alunas no contexto cibercultural, não apenas apresentando o AVA Moodle e suas ferramentas, que vale salientar a maioria dos discentes não conhecia, como acessando o Facebook e criando contas de quem ainda não acessava tal rede, que eram poucas alunas. Propomos neste momento duas atividades, uma no Moodle, que foi um fórum temático de apresentação dos alunos e outro para discussão sobre a "Concepção docente", onde deveriam expor suas opiniões acerca dos sentidos da profissão docente. Aproveitamos também para ir além, buscando inserir as alunas em outras redes sociais, apresentando as ferramentas do Google Docs, que possibilitam o trabalho colaborativo, de modo a fazer com que adentrassem o universo maior das tecnologias e pudessem refletir de que maneira poderiam utilizá-las em suas práticas como futuras docentes.

Nas aulas presencias que tivemos, os conteúdos eram discutidos com base na leitura dos textos sugeridos bem como pelas temáticas afins e problematizações ocorridas no ambiente virtual, e este ir e vir do presencial ao virtual concretizou um processo formativo muito rico, dialógico, onde todos os discentes participavam ativamente dando suas opiniões, colocando suas dúvidas e sendo autores e coautores do conhecimento, indicando outros textos, vídeos, links interessantes, enfim, aprendendo a aprender de forma colaborativa. 
Desde o início da disciplina, em ambos ambientes, divulgamos links para textos, vídeos, músicas, eventos, enviamos avisos sobre leituras indispensáveis, compartilhamos fotos dos momentos vivenciados pelos alunos em sala de aula, sugerimos que os alunos buscassem textos, imagens ou vídeos sobre tecnologias e seus usos nos processos de ensino e aprendizagem à distância, ou seja, realizamos um trabalho paralelo em ambos ambientes pedagógicos.

No Moodle, realizamos foram propostos 4 fóruns temáticos na disciplina: $\mathrm{O} 1^{\circ}$ e o $2^{\circ}$ respectivamente Concepções Docentes e Redes Sociais como Dispositivo Pedagógico, participaram 16 alunos, que representam $69 \%$ do total de matriculados; O $3^{\circ}$ intitulado Cursos Híbridos ou Blended Learning, participaram 7 discentes, representando $30 \%$ e o $4^{\circ}$ sobre Mediação Pedagógica e Ecologias Cognitivas, participaram apenas 6 discentes, o que equivale a $26 \%$ dos alunos.

Apesar de o Moodle ter sido percebido pelos alunos como um ambiente com teor interativo mediano, em comparação ao Facebook, ele era muito menos freqüentado diariamente. Como todos os avisos e discussões eram suscitados em ambos ambientes pedagógicos, percebemos que os retornos dos alunos se davam de forma mais rápida no Facebook, que respondiam quase de forma síncrona as nossas orientações. Isso ocorreu,segundo os próprios alunos, pelo fato de estarem constantemente conectados à citada rede social bem como pode ser reflexo da maior dinâmica do desenho didático do Facebook, que possibilita maior interatividade, compartilhamento de informações de forma prática e rápida, participação dos discentes como autores, conhecimento da vida social dos companheiros e sentimento de pertencimento, entre outros. É como se o Moodle fosse visto de certa forma como um ambiente mais estático, engessado, um mundo paralelo, uma sala de aula à parte do que está acontecendo no mundo.

No decorrer do semestre, ainda vivenciamos duas aulas totalmente online, utilizando especificamente as interfaces interativas destes ambientes: uma, que foi um chat temático no Moodle, onde buscamos tirar as dúvidas dos conteúdos tratados até o momento bem como motivar as discentes a construção compartilhada do saber. Como praticamente quase todas as discentes adentraram o chat, acabou que a experiência não foi tão significativa, por 
problemas técnicos, uma vez que caia bastante tal ferramenta, bem como quando era reestabelecido o contato acabava que as conversas paralelas interferiram no objetivo inicial. Contudo, consideramos este um momento importante por as alunas poderem ter vivenciado minimamente o uso desta ferramenta. A outra atividade online ocorreu no Facebook, cuja proposta foi a de que os alunos deveriam discutir a temática da semana, compartilhando qualquer tipo de mídia relativa ao assunto em questão, além de escolherem, lerem e comentarem a publicação dos companheiros. Este momento foi riquíssimo, os alunos interagiram bastante, postaram diversos textos, links, vídeos, figuras, a discussão foi de intensa colaboração.

A atividade presencial foi proposta enquanto um seminário, sobre assuntos relacionados as discussões tidas até então na disciplina de Introdução à Educação a Distância. A turma foi dividida em grupos e incentivada a discutir e elaborar o trabalho nos ambientes pedagógicos Moodle, onde fóruns foram abertos por grupos para tal debate, e no grupo do Facebook. As alunas interagiram em ambos espaços e os seminários também se consolidaram como um momento significativo, por ter sido realizado pelas discentes de forma dinâmica, com o uso de tecnologias diversas, sendo um momento de trocas, de debate intenso, e não mera exposição, como ocorre na maioria dos seminários.

A experiência de utilizar o Facebook como ambiente pedagógico foi bastante agregadora e positiva para a construção do conhecimento dos alunos, pois este espaço se consolidou como uma sala de aula viva, com contribuições constantes dos próprios alunos acerca das temáticas pontuadas na disciplina e, muito além desta, pois os alunos se sentiam à vontade para partilhar conhecimento de origens diversas como, por exemplo, sugestões de sites, congressos, eventos da área, potencializado assim o sentimento de união da turma e a criação de uma verdadeira rede de aprendizagem. A colaboração e a troca de conhecimentos foram intensas nesta rede social. O Moodle, apesar de ter sido muito menos frequentando pelos discentes também foi espaço rico de aprendizagem e extensão das discussões em sala de aula.

Portanto, percebemos que o Blended Learning foi uma experiência riquíssima do ponto de vista que o conhecimento na sociedade digital precisa sair das barreiras sólidas das salas de aulas presenciais e se abrir para novas possibilidades tidas no Ciberespaço. Construir 
o conhecimento foi além do tempo espaço, e as discentes puderam perceber a importância das tecnologias como espaço de inclusão social, de educação, e principalmente da ressignificação da educação a partir das tecnologias digitais, considerando esta experiência como construtiva, inovadora e favorecedora de novas possibilidades educativas em suas futuras práticas pedagógicas enquanto docentes.

\section{Considerações Finais}

A partir da análise da experiência, pode-se concluir que o Blended Learning potencializou o processo educativo, possibilitando um processo de ensino aprendizagem mais flexível, com maior autoria por parte dos discentes, os quais se sentiram motivados e consideraram uma rica experiência, inovadora e que possibilitou abrir o olhar para novas práticas educativas, que é de fundamental importância uma vez que serão futuros educadores.

Percebemos a importância de se refletir sobre esta nova forma de se conceber a educação de forma que novas práticas possam ser realizadas e compartilhadas através de pesquisas, e assim possamos caminhar no sentido de uma educação mais plural, interativa, colaborativa, flexível, enfim, mais humanizadora.

\section{Referências Bibliográficas}

BRASIL, Ministério da Educação. Portaria n. 2.253, de 18 de outubro de 2001. Brasilia, 2001.

HINE, C. Etnografía Virtual. Editorial UOC: tradução para o espanhol por Cristian P. Hormázabal. Colección Nuevas Tecnologías y Sociedad, 2000.

KERBAUY, Maria Teresa Miceli; SANTOS, Vanessa Mato dos. Redes sociais educacionais mediadas por computadores. In: BARROS, Daniela Melaré Vieira et. al. (orgs.) Educação e tecnologias: reflexão, inovação e práticas. Lisboa, 2011. (e-book) p. 266 - 298. Disponível em:<http//livroeducacaoetecnologias.blogspot.com/> Acesso em: 04 jul. 2011.

KENSKI, Vani Moreira. Educação e tecnologias: o novo ritmo da informação. Campinas, SP: Papirus, 2007.

LAVILLE, Christian; DIONE, Jean. A Construção do saber: manual de metodologia da pesquisa em ciências humanas. Porto Alegre: Artmed, 1999. 
LEMOS, André; Cunha, Paulo (orgs). Olhares sobre a cibercultura. Sulina, Porto Alegre, 2003; PP.11-23).

LÉVY, P. Cibercultura. São Paulo: Ed. 34, 1999.

MANSUR, Andre F. Uebe; CARVALHO, Rogerio A. de; BIAZUS, Maria Cristina V. Redes de saberes coletivos (Resa): um ambiente complexo para a aprendizagem acadêmica por meio de redes sociais. Anais do XXII SBIE- XVII WIE, Aracajú, 2011.

MINAYO, Maria Cecília de Souza. Pesquisa Social: teoria, método e criatividade. 18 ed.Petrópolis, RJ: Vozes, 2001.

PEREIRA, Ana Maria de O; TEIXEIRA, Adriano C. As tecnologias de rede como espaço de aprendizagens significativas em Geografia. Anais do XXII SBIE- XVII WIE, Aracajú, 2011.

RABELLO, Cinta Regina Lacerda; HAGUENAUER, Cristina.Sites de Redes Sociais e Aprendizagem: Potencialidades e Limitações.In: Revista EducaOnline, Vol. 5, no 32011.

RECUERO, Raquel. Redes sociais na internet. Porto Alegre: Sulina, 2009.

SABBATINI, Renato M.E. Ambiente de Ensino e Aprendizagem via Internet. A Plataforma Moodle. Instituto EduMed. Disponível em $\langle$ http://www.ead.edumed.org.br/file.php/1/PlataformaMoodle.pdf $>$. Acesso em $30 / 05 / 2012$.

TORI, Romero. Cursos híbridos ou blended leraning. In: FORMIGA, M.; LITTO, F. Educação a distância: o estado da arte. São Paulo: Pearson Education, 2009.

UNIVESIDADE ABERTA DO BRASIL. Disponível em: http://uab.capes.gov.br/ Acesso em $30 / 05 / 2012$. 